\title{
TOPmodels and Top Designers: \\ Forms of Social Interaction and Creativity in the TOPmodel Online Forums
}

\author{
Mari Mäkiranta ${ }^{1}$ \\ Post-doctoral Researcher, University of Lapland, Finland
}

\section{doi:10.5937/comman1329061M}

Summary: The TOPmodel brand contains products for girls aged 7-15, such as notebooks, colouring books, accessories, and pens and pencils. The brand has also a website and an active online community, whose main purpose is to advertise TOPmodel products and provide information on how to learn about fashion, beauty, and consumerism. In this article, I explore the English version of the TOPmodel website (http:/len.topmodel.biz/index_en.html), and ask what kind of social interaction the TOPmodel online forums enable for children, especially girls. What kind of creativity can be found from the contents and girl' actions within Web 2.0, and in what terms? Discourses of children's media use have varied from worry about their actions to the many possibilities of online participation. On the one hand, children are seen as vulnerable to the commercial contents of the Internet, which is filled with different brands and effective marketing aimed at young people. On the other hand, there has been an increasing interest in children creating their own cultures and online content. This article focuses mainly on the latter perspective: I study the possibilities of children's self-expression, creativity, and ability to share and discuss different topics with each other. I define girl' Internet use as a sense of formability and belonging, which explains how girls participate in constructing the TOPmodel brand, create online content and engage intensely in virtual community. A sense of formability and belonging also refers to girls possibilities to reformulate the predefined online topics, create alternative designs and form social relationships within online forums. My analysis is based on empirical data from six months of ethnographic participatory observations of online activity.

Keywords: girlhood, Internet, online community, self-expression, social interaction, gender, creativity

\footnotetext{
1 mari.makiranta@ulapland.fi

Article is part of the author's post-doctoral studies related on young people's social agency and creativity in the fields of media culture. The study is funded by the Finnish Cultural Foundation and the University of Lapland.
} 


\section{Introduction}

When following the TOPmodel online forums in turn of the years 2012 to 2013, I experienced the girls' world, which is in two essential ways different than girl cultures such as my youth in the 1980s. The topics girls talk about have not really changed: we also talked about friendships, clothes, and personal problems, and we played with paper dolls and drew a lot, just like the girls who belong to the TOPmodel community seem to. Nevertheless, two main things have changed: in the Internet era, girls' actions can take place online, within certain virtual communities; and the virtual platforms that are specified for their play and communication are often provided by different brands. This means that consumer cultures and online publishing are part of girls' everyday experiences. Girls who belong to the TOPmodel virtual community face the fact that their drawings have a wider and more international audience, and the topics they talk about can have thousands of readers and evoke as many replies and comments. The TOPmodel online community seems to be an important meeting point for thousands of users, and it has been claimed that forming social networks within interactive Internet environments is a cultural phenomenon that affects young people especially, and increasingly children (Hodkinson and Lincoln, 2008). It has also been stated in various surveys and studies that children and young people who use the Internet in their daily lives are fascinated about the possibilities of using the Internet especially for entertainment and fun, and for communicating with others (Hodkinson and Lincoln, 2008; Laukkanen, 2007; Livingstone, 2003; Mazzarella, 2005; Paasonen, 2009). Richard Butsch and Sonia Livingstone (2013: 2-4) point out that discussions on audiences should not be reduced only to aspects of leisure and entertainment, but should be formulated in ways that link media use, for instance, in cultural improvement as well as a means of social control. This means that children as Internet users and content producers are embedded in discourses of power, representation, and regulation in distinctive yet overlapping ways according to specific socio-historical contexts -in this case the virtual and global community of TOPmodel brand in 2013.

The popularity of the TOPmodel site can largely be explained by the Internet's ability to offer platforms for social networking and participatory culture. Henry Jenkins (2006), and Aaron Delwiche and Jennifer Jacobs Henderson (2013) note a shift toward media convergence and participatory culture: Web 
2.0 technologies are integrated smoothly, and services are accessed by wide populations to create and share content. This has made it possible to utilize different kinds of online forums that allow young people to express themselves, engage in virtual communication and sharing, and discuss different topics with each other. Addressing the possibility of self-expression, although, cannot be taken for granted: discourses on children's media use have varied from worry about their actions to the possibilities for online participation. On the one hand, children are seen as vulnerable to the commercial contents of the Internet, different brands, and effective marketing aimed at young people (Mazzarella, 2005). On the other hand, there has been increasing interest in the possibility of children being able to create their own online cultures and contents (Reid-Walsh and Mitchell, 2004). From the latter perspective, online forums have the potential for empowerment: online community members can create contents, discuss their interests, and voice support for the things they feel strongly about, especially if they come from each other. In this article, I explore the virtual world of the TOPmodel brand and ask what kinds of creativity the TOPmodel online forums enable for children, especially for girls. What kinds of forms of social interaction can be found in girls' contents and actions within the Internet, and in what terms?

TOPmodel is a global brand that consists of material things such as TOPmodel magazines, colouring books, note pads, pens and pencils, beauty accessories, bags, purses and pencil tubes, and "sweet gifts for you and your friend", as advertised on its web page. The company's target group is young girls between 7 and 15 years of age. Annamari Vänskä and Minna Autio (2009), who have studied childhood representations in visualized consumer cultures, note that research on childhood as part of a consumer culture is important due to the fact that children are targeted for and provided with increasing amounts of products and services. For me, this notion of childhood and consumerism was realized while I was studying online communities: increasing amounts of products and services are available for young people online, and the practices and meanings that children and young people give to themselves and their actions are being formulated according to the whims of the cyber and consumer cultures.

TOPmodel's online community's main goal is to advertise TOPmodel products and provide girls with possibilities to learn about fashion, beauty, and consumerism. In other words, the TOPmodel website and online forums 
offer a portal to TOPmodels' world and products. The website has a "feminine design", as Susanna Paasonen (2009: 7) puts it. The site's pages are mainly pink and decorated with hearts, stars, and flowers. The site's visual form, aesthetics, and contents are designed to appeal to girls of a certain age group and thus persuade them to be part of the TOPmodel brand and virtual community. It could be said that the girls who join and get attached to the TOPmodel virtual community take part in constructing the TOPmodel brand. Muniz and O'Guinn (2001) and Sicilia and Palzón (2007), who have studied online advertising, state that brand community refers to the communality that is being built up around certain trademarks, and that has its own values and rituals. The TOPmodel website can thus be seen as a brand community, in which users can discuss the topics they find interesting, get attached to each other, and be part of the brand. The TOPmodel brand serves as proof of the wider cultural phenomenon that closely links children's' identity construction to consumerism.

The contents of the TOPmodel products are intertwined with 13 different TOPmodel characters and their profiles. All characters have the outlooks that can be associated with cultural stereotypes of femininity. One example is the romantic Candy, who is 1.75 meters tall, has blue eyes and blond hair; whose birthday is on $11^{\text {th }}$ November; and whose star sign is Scorpio. Candy's favourite item is a pink tulle skirt, and her hobbies are video dancing and playing with her pug, Prince. She describes her style as pretty romantic, and she shares flat number 1 with her best model friends, Fergie and Christy. Her motto is "I love life," and she characterizes herself as having freckles. Mops are her favourite animals, and the rose quartz - the love stone - is her favourite jewel.

The significant difference between the 13 characters does not lie in their varied lifestyles or appearances - they love shopping, new clothes and "looking good”, but in their assumed cultural backgrounds. Despite Miju and Nyela, all the other TOPmodels symbolize whiteness as a norm, and all characters signify consumerism and hegemonic beauty ideals. While looking at the TOPmodel characters, it is not difficult to understand the critics of these kinds of representations, which are claimed to strengthen stereotypes, and damage children's self-conceptions (Livingstone, 2003; Reid-Walsh and Mitchell, 2004). In this sense, the TOPmodel characters could also be said to maintain narrow cultural ideals of femininity, especially when taking into consideration female protagonists and antagonists that challenge narrow cultural norms of femininity in the 
popular literature, television, comics, videogames, and other new media since the 1990s (Inness, 2004). Contemporary media culture positions empowered women in speculative fiction, but TOPmodel characters seem to maintain narrow cultural representations with commercial engagements and address prevailing conceptions of gender, race, sexuality, class, and nation.

Even if there is no doubt as to the TOPmodel brand's engagement in consumerism and hegemonic ideals of femininity, I am not highlighting the harmful aspect of these kinds of representations. Instead, I am focusing on the meanings and practices that the girls themselves give for their actions inside the TOPmodel online forums. My aim is to find out the ways for girls' self-expressions and participatory actions, and define their attraction to the Internet. In the article I claim that girls' actions within the TOPmodel virtual community can be understood as a sense offormability and belonging. Sense of formability and belonging refers, first, to girls' creative online actions such as drawing designs and playing online; second, ways of networking and building social relationships virtually. Sense of formability and belonging also characterizes how girls participate in society and construct their social agency in virtual and material worlds. This means that I understand online forums as virtual environments that are closely linked to the physical world and materiality. Gender, in the context of cyberspace, can, thus, be defined as a lived social relationship (McNay, 2004) and a system of multidimensional, dynamic differences and power: both discursive power and material conditions make up the gender systems and gendered interpretations that can be found within the online communities. I also emphasize the differences and diversity of gendered subjects and social relations. Gender can also be understood as cultural and social, as well as verbal and visual performances constructed through continuums and repetition (de Lauretis, 1987; Butler, 1990; 1993). This repetition, like associating shopping and fashion with girls, can be challenged but not less-valued, only because the actions are being defined as feminine in our culture, as well as in the TOPmodel community.

\section{Getting into Girls' Worlds and Defining Methodology}

The data explored here consist of the contents of the English version of the TOPmodel website. The site has seven main categories: Creative Studio; Community \& Message Board; Comp Card; Tips, Tricks \& Tests; TOPmodel 
World; Play \& Win, and Boutique. I have defined for closer examination two forums: the Creative Studio and the Community \& Message Board.

From August 2012 until the end of January 2013, I have systemically followed the TOPmodel online forums. Due to the fact that the flow of discussions and creative materials sent to the site are enormous and constantly changing, I chose to save data for three days per week. The amount of empiric data is enormous: between 150 and 200 drawings were sent to the online community each month. In addition, there are about 800 designs on the Latest Designs page. The topics of the Message Board can have 200 to 2000 subjects with up to 90 responses, not to mention the massive number of discussions taking place in chat rooms. The data I collected over those six months, however, constitute an informative sample of the common contents produced for and in the TOPmodel online world. This sample indicates the girls' actions, thoughts, and the meanings they give to themselves and their experiences within that online community.

Eleven different languages are available for use with the main TOPmodel virtual forum. I chose to explore the English version since some members of the forum come from different regions and countries, and some of use a language other than English as their mother tongue. The English forum probably shows the widest and most diverse sample of members in the TOPmodel community; it includes participants from Great Britain, Finland, Germany, Norway, and the Netherlands, just to name a few. It is also worth noting that ability to use English is only essential on the Community \& Message Board. In the Creative Studio, even very young children can easily interact without knowing much English, since it emphasizes children's visual designs, drawings, and creations, as well as-on a smaller scale_-verbal communication, like commenting on others' designs and reading comments.

The methodological and theoretical basis of my analysis lies in virtual ethnography and post-structural feminist thinking. I apply virtual ethnography (Campbell, 2004; Hine, 2000; Laukkanen, 2007) in the sense that I systemically followed the virtual community and online discussions. I participated in the community's actions in real time by following discussions and creating my own styles and TOPmodel outfits in the Creative Studio. I have been a registered user of the site, as registered users are allowed to post comments on the Community \& Message Board and in the Creative Studio. I decided not 
to take part in any conversations due to the fact that I am older than most of the active members of the TOPmodel community, and I did not want to affect their discussions. I also would have felt uncomfortable giving instructions or opinions on other users' designs, although the comments are mostly supportive and constructive. Instead, I chose to take my data from the forums, which are available for any visitor to read (see Markham and Buchanan, 2012).

Post-structural feminist thinking, particularly Butler's (1995) idea of social agency, inspires my analysis. Butler states that social agency becomes concrete and real in the variation of cultural models and in the possibilities of altered repetition. The online forums examined here are constructed as ordinary, but at the same time portray hidden and unconscious practices that have a strong impact on girls' lives; they denote and determine what kinds of performances, actions, and discourses are accepted within the forums. The productive concept of power, as Foucault (1980) puts it, enables the idea in which hegemonic visual and verbal representations offer the models the opportunity to self-identify, but they also provide the space for resistance. For me, it is fascinating to think about what kind of resistance can actualize within the global brand that provides ready-made platforms for drawing and design, emphasizes consumerism and hegemonic beauty ideals, and has moderated and regulated space for online actions.

\section{Drawing and Playing Online}

The Creative Studio has three subpages: Wardrobe, Drawing School, and Designer Table. In Wardrobe, the user can choose between five different pages: My Wardrobe, Shopping World, My Outfits, Create Your Style, and Friend's Outfits. In My Wardrobe and Shopping World, a user can style TOPmodels to their own taste and virtually shop for new clothes from cities like London, Paris, Madrid, Berlin, and Amsterdam. On the Create Your Style page, a user can use design a studio to create t-shirts, dresses, and handbags that use different colours, textures, prints, and so on. In this section, it is also possible to use design tools, name your own designs, and save them in My Outfits. The My Outfits page includes different categories for different occasions; the member can save their creations for categories like street fashion, party dresses, glamour pure, rock chick, sport outfit, couch looks, fashion no-gos, and more. Other members' designs can be uploaded on the Friend's Outfits page. 
In Drawing School, different themes show how members can draw their own creations. For example, the Drawing School theme in January 2013 was clothes with different textures. There were also instructions on how to draw an outfit for a pet dog, how to create a Vanessa Hudgens look, how to apply makeup like a professional, how to draw hair, and how to achieve a perfect blond highlighted look.

In Designer Table, the main idea is to create your own designs and then share them with other members and viewers. From Designer Table, users can find the categories of Designer Charts, Latest Designs, My Designs, Friends' Designs, Design Themes, My Favourites, Creative Crew, and Colouring Templates. Designer Charts shows the most popular designs of the week, month, year, and all time, as well as the TOPmodel team's favourites. Design Themes includes the General, Faces \& Make up, and Stars categories. It also includes Glamour, T-shirts, Hands and Nails, and Animals. On this page, users can take a photograph, upload their own creation, and send it to the forum. Forum members can rate drawings on a scale of 1 to 10 glittering stars, and can also leave comments.

On the Creative Studio page, users can modify their TOPmodel characters' outfits, dressing and undressing them with a wide selection of clothes. This action happens on the Wardrobe page, which is a bright, open, spacious space, with all the clothing set in a good order. In the back of the virtual room is a makeup kit on a dressing table, with a chair and a shopping bag blithely forgotten on the floor. The dressing table, makeup, and shopping bag give an impression of the girlhood that is determined by a certain ideology: in our contemporary culture, childhood does not remain outside the consumption and hegemonic ideals of beauty (Vänskä and Autio, 2009).

The attraction of the Creative Studio lies not only in the possibility of creating the perfect and normative outlooks for the TOPmodel characters, but also in the possibilities for play. As Paasonen (2009) puts it, the constant variability of the characters can be seen as a satisfactory action and can be connected to the traditional act of playing with paper dolls. Even the virtual Wardrobe space is very limited in providing just one room for action, and even the garments available in the beginning of the virtual play experience are sparse; however, the play space of the online forum is constantly expanded and reformulated with great imagination. While dressing and undressing their characters, users form 
emotional bonds with their characters and invent different kinds of life narratives, stories, and happenings related to the characters that go beyond the given virtual room.

On the Drawing School and Designer's Table pages, users can learn how to draw TOPmodel characters; drawing skills are improved with the help of detailed tips, patient practice, and other users' feedback. On some occasions the feedback is detailed and professionally focused on the composition, use of lines and colours, and definition of drawing styles. Usually the feedback is, thus, not focused on the drawers' technical merits, but is generally supportive and even full of praise, like comments to Luliet:

SO AWESOME!!!!

(anne4525, April 04, 2013, at 08:56 a.m.)

"WOW! Youre really good at designing and drawings. Well done. :D"

(jaspig, April 03, 2013, at 08:15 p.m.)

"so cool $i$ wonder how $u$ do it because it looks so hard with all the details and your great sence of fashion"

(cadiumgold, April 03, 2013, at 02:24 p.m.)

The play with the TOPmodel characters and the feedback received from the online community is part of the girls' identity construction and aesthetic experiences. Päivi Granö (2010: 109) who has studied online galleries, address young peoples' tendency "to think with their hands". This kind of action, like drawing the TOPmodels and sharing those drawings' designs within the online community, contains two things. The first is the personal level for selfexpression and forming the subjectivity by doing material things. The second is the aesthetic experience, which contains the social level: sharing a drawing is essential because doing so can help one construct a positive self-image and increase their personal skills. Finally, the aesthetic experience includes the cultural level in which the cultural symbols are being utilized and interpreted. In the era of the Internet, designing TOPmodels creates the aesthetic experience of young people; one's favourite TOPmodel character's skin colour, hair, facial expressions, clothing, and environment can be varied and used to depict the drawers' personal emotions, moods, and lifestyles. 
Even the drawings sent online are usually produced on the TOPmodel templates found in Design Books, the TOPmodel drawings can get an alternative and surprising outlook in commercial and consume-driven TOPmodel brand's and context. Widawewoos's drawing depicts the Red Nose Day TOPmodel character (Figure 2), who carries the Red Nose Day sign like a statement for charity. The Red Nose Day design emphasizes the unique and funny outfits that can be associated with childhood clothes, rather than mimicking adult clothing like those designs that are usually seen on the TOPmodel website. The design's distinctiveness has been noticed in the TOPmodel virtual community:

"this is pretty unique!"

(Funandcake, March 04, 2013, at 03:29 p.m.)

"funny! i love it!"

(catandpony39, March 30, 2013 at 07:11 a.m.)

The design called Pretty Future Recycling (Figure 1) refers to the possibility of reformulating the TOPmodel brand and its ready-made design templates. The designer writes, "I called it Pretty future recycling cos it was for a future comp and the dress looks like post-it-notes!" (Widawewooo, March 01, 2013, at 04:42 p.m.). This excerpt shows that even the virtual space for selfexpression and creativity is very limited within the TOPmodel forum, and that the community's ideological message provides only a normative, consumerist worldview; girls are able to challenge that order. Alternative designing makes it possible for users to reformulate the given ideology and provide their own terms and methods of self-expression.

\section{Girls' Topics: Friendship and Support}

The Community \& Message Board page has four subpages: Best of Community, Message Board, Friend Finder!, and TOPmodel-Chat. On the Best of Community page members can find out who the newest users are, as well as who are the most active and popular members of the community. On the Message Board, users can discuss different "topics, gossip, give advice, pour your heart out, solve problems, and give valuable tips.” Related topics are Fashion \& Styling, Make-Up Tips, Facial Care, Beautiful Hair, Body Care, Designer 
Table, Friends Help Friends, Heartache, First Aid for Love and Relationships, and Stars \& Celebrities. The Friend Finder page is advertised as the TOPmodel community's "meeting place for lots of online fans": "Life in a virtual community is the most fun when there are lots going on, the members play an active part and find friends and swap ideas. Here we can help you to make new friends and meet other interesting people." Friends can be found by filling in their username, or by searching for them on the basis of characteristics such as sex, age, star sign, eye colour, hair colour, school, and country. In the chat rooms, members can meet their friends or other members in one of the model's chat rooms. Chat rooms are open daily 10:00 a.m. to 08:00 p.m., and are named after the TOPmodel characters: chat rooms include Christy's Dressing Table; Hayden's Desk; Miju's Lounge; Flat's Fireplace Room; Jenny's Chaotic Room; Nyela, Talita \& Louise's Roof Garden; Flat's Kitchen; and VIP Chat. TOPmodel's Community \& Message Board is a perfect example of the common perspective in media and communications studies in which media audiences are understood as active participants and content producers rather than as passive consumers of mass media. TOPmodel brand as any other corporations utilize the activity of their target groups by providing them with different kinds of interactive online platforms for their use (Jenkins 2006).

The term Web 2.0 describes the activity of media audiences and the importance of the content produced by users to improve and support Web concepts and business ideas (O’Reilly, 2005; Paasonen, 2009; Sicilia and Palazón, 2007). Online participation is based both on the users' volunteering to produce the virtual content and their adherence to the social cohesion between the online community's members. According to Jenkins (2006), the ideal member of a Web community is an active, highly committed, socially networked person. TOPmodel's Community \& Message Board produces this kind of action by providing opportunities to form strong relationships between users, who invest a lot of time and effort in participating in and creating online content.

For its users, TOPmodel's virtual world provides possibilities for personal friendships that consist both of the TOPmodel characters and real human beings; TOPmodel characters are the central part of the community in the sense that they provide the personalized spaces for the users' conversations and models for identification, such as forming sisterly care towards each other. The social relationships formed between the users are shaped inside social media, 
which provides the space users need to solve everyday problems. For example, at 08:05 p.m. on January 07, 2013, Tiara wrote on the Friends Help Friends discussion board:

"so i want to make a club called "thats what friends are for" because i think that we get a lot of friend problems and arguments so you can tell it here and anyone who joins the club can help you answer it anyone can join the club any problems or worries this is the place to ask for help and advice! plus whoever joins i will write in their guestbook! please join!"

A day later, Lily32 responded (at 05:05 p.m.):

"I want to join in! I have a problem already (I don't know does it relate to this topic, but I hope you can give advise) I'm shy, so everytime I'm with my friends and their friends! They are loud and they talk all time, but I'm just quiet, I just don't figure out what to say! I'm going to new school I don't know anybody from there, so I want to get friends! but I don't know how because I'm shy!"

Less than 30 minutes later (at 05:31 p.m.), Lily32 got a response from talita-star, who wanted to show her support:

"well when you move to a new school its kinda like reinventing your self, you get to start again. just be friendly \& you ought to find someone that returns the smile:) if your given an assignment (with someone) thats a great way to start!"

The community's support on sensitive topics, forming friendships and identities within social groups is distinctly exhibited in the exchanges between Tiara, Lily32, and talita-star. These excerpts remind of the Web's connection to real life: the topics girls discuss online are constructed in different virtual spaces but are closely related in socio-cultural and material contexts. Socio-cultural and material contexts can be related to the issues in the girls' everyday lives, but also to so called supervisory eyes: the girls' actions online are being closely watched both within their families and on the online community's moderators. Anikka Suoninen (2013), who has studied 10-12-year-old Finnish children's media use, points out that parents take a closer look at girls' Internet use than boys'; for example, boys are more often allowed to have an Internet connection on their mobile phones than girls are. Girls tend to be more careful in who they trust in online forums, and to whom they reveal their personal details. In 
addition, girls are choosy about who they accept as friends in online services, and about the kinds of things they write about online (Suoninen, 2013). This phenomenon can be partly explained by real-life situations: girls' actions are being regulated more carefully than boys', in the same way that femininity in our culture is seen as being in need of protection. In TOPmodel's case, the fact that girls carefully consider what and how they write and communicate can be justified by the fact that many users seem to be skilful media users who obediently follow the TOPmodel community's rules and cyber ethics. For example, cyber bullying and "in real life" harassment intensely looked down upon in the forums. For example, at 09:12 p.m. on January 18, 2013, Toopers wrote:

"Bulliying is horrible and if this ever happens to you please tell me on my message board (which is on body care) Rough Time At School? or if you want to be more personal you can become my friend and tell me on private messages. On my message board isnt just for bulliying it is for anything and now you can do anything not just at school. Also remember you can send me a personal message aswell. Thank you :) :) :) :) :) :)"

The TOPmodel moderators predefine the topics, still girls maintenance form the discussion platforms to their own needs. For example, on the Fashion $\&$ Styling discussion board, users can talk about subjects completely unrelated to fashion design. At 10:57 p.m. on March 09, 2013, happyrobin wrote a post entitled “OMG SO NERVOUS HELP!!!!?”:

"Ok so $i$ have got my grade 3 violin exam on tuesday (12 march) please help $i$ am so nervous its my 2 nd violin exam ( $i$ skipped grade 2 ) but the optamistic side is that $i$ did get a destinction (the highest grade) so that boosted my confidence but 3 days before my exam my nerves are shattering me. HELP HELP HELP!!!!!!"

She got answers from nicole5989 at 12:24 a.m., from TOPmodelvampire at 05:04 a.m., and from WildViolet at 06:31 a.m. on March 10, 2013. They gave her advice, saying:

"Just think of things you love"

"PRACTICE" 
"Ya know the buzz, Keep Calm stuff, Keep calm and carry on (I say keep calm and love Bridgit Mendler, but now is not the time:-) If you make a mistake or five, so what? Carry on, don't let or yourself make you nervous! Focus on the piece, pretend that you use the violin to speak. And we all know you're going to do really really well! Hope I helped, Wild xoxo"

happyrobin answered at 02:46 p.m. the same day: "thanks it did".

These excerpts depict how different practices, such as discussions about playing the violin or making a friend at a new school, produce the category and definition of girlhood, which goes beyond such established TOPmodel categories as fashion, outlook, and consumerist lifestyles. When girls show solidarity towards each other, and when they use predefined discussion boards to talk about their own created topics, they are simultaneously formulating the cultural category of girlhood and deconstructing the moderated and strictly restricted TOPmodel virtual space to meet their needs. Girlhood in the context of TOPmodel's virtual world turns out to be culturally and socially produced, re-produced, and deconstructed in girls' everyday Internet use. The flexibility and creativeness in girls' Internet use, as well as the contents of their discussions, develop different understandings of the narrow cultural and social activities, such as fashion and beauty that are associated with girls. Girls' activities can thus be understood as discursively inscribed, various, and flowing (see also Ylitapio-Mäntylä, 2011).

\section{Conclusion}

Although the young people live in a world where Internet and new technologies diminish the meaning of a materiality and promise ever-increasing powers of disembodied mobility and the creation of new identities, the meaning of the material context of life has not lost its importance: human beings cannot be isolated from the social, material and emotional conditions of their immediate surroundings. The TOPmodel platform appears as cultural, virtual and material space for resistance; new ways of expressing the self become visible, with a significant role to play in challenging consumerist lifestyles and reformulating the predefined topics. Within the ready-made commercial community, girls open up alternative visual worlds by challenging and reformulating TOPmodel ideol- 
ogy and given cultural categories. The possibilities for creative self-expression, participatory action, and communality, as well as transforming the material play and designs online, increase girls' attraction to the Internet. I suggest, thus, that girls' engagements within the TOPmodel virtual community can be defined as a sense of formability and belonging. The idea describes girls' contribution in constructing the TOPmodel brand and engaging intensely in virtual community. Sense of formability and belonging refers also to girls' potential to reformulate the restricted virtual space and characterizes how girls participate in society and construct their own social relations within virtual and material worlds. 


\section{References}

Butler, J. (1990). Gender Trouble: Feminism and the Subversion of Identity. London: Routledge.

Butler, J. (1993). Bodies that Matter: On the Discursive limits of "Sex". London: Routledge.

Butler, J. (1995). For a Careful Reading. In Benhabib, S., Butler, J., Cornell, D. \& Fraser, N. (eds.), Feminist Contentions: A Philosophical Exchange. New York \& London: Routledge, pp. 127-145.

Butsch, R. \& Livingstone, S. (2013). Meanings of Audiences. Comparative Discourses. New York: Routledge.

Campbell, J. E. (2004). Getting It on Online: Cyberspace, Gay Male Sexuality, and Embodied Identity. New York: Harrington Park Press.

de Lauretis, T. (1987). Technologies of Gender: Essays on Theory, Film and, Fiction. Bloomington: Indiana University Press.

Delwiche, A. \& Henderson, J. J. (2013). Introduction: What is Participatory Culture. In Delwiche, A. \& Henderson, J. J. (eds.), The Participatory Cultures Handbook. New York: Routledge, pp. 3-9.

Foucault, M. (1980). The History of Sexuality: Vol, 1. An Introduction. New York: Wintage.

Granö, P. (2010). Kuvataidegalleriat nuoren esteettisenä vapaatilana. In Brusila, R. \& Mäkiranta, M. (eds.), Kuvakulmia 2: Kirjoituksia kuvista, taiteellisista tuotannoista ja visuaalisista viesteistä. Rovaniemi: Lapland University Press, pp. 101-118.

Hine, C. (2000). Virtual Ethnography. London: Sage.

Hodkinson, P. \& Lincoln, S. (2008). Online Journals as Virtual Bedrooms? Young People, Identity, and Personal Space. YOUNG, 16(1), 27-46. 
Inness, S. A. (2004). "Boxing Gloves and Bustiers": New Images of Tough Women. In Inness, S. A. (ed.), Action Chicks. New Images of Tough Women in Popular Culture. New York: Palgrave \& MacMillan, pp. 1-26.

Jenkins, H. (2006). Convergence Culture: Where Old and New Media Collide. New York,: New York University Press.

Laukkanen, M. (2007). Sähköinen seksuaalisuus: Tutkimus tyttöydestä nettikeskusteluissa. Rovaniemi: Lapland University Press.

Livingstone, S. (2003). Children's Use of the Internet: Reflections on the Emerging Research Agenda. New Media and Society, 5(2), 147-166.

Mazzarella, S. R. (2005). Introduction: It's a Girl Wide Web. In Mazzarella, S. R. (ed.), Girl Wide Web: Girls, the Internet, and the Negotiation of Identity. New York: Peter Lang, pp. 1-12.

Markham, A. \& Buchanan, E. (2012). Ethical Decision-Making and Internet Research. Recommendations from the AoIR Ethics Working Committee (Version 2.0). Accessed 23.9.2013. URL: http://aoir.org/reports/ethics2. pdf.

McNay, L. (2004). Agency and Experience: Gender as a Lived Relation. In Adkins, L. \& Skeggs, B. (eds.), Feminism after Bourdieu. Blackwell: Oxford, pp. 175-190.

Muniz, A. \& O'Guinn, T. (2001). Brand Community. Journal of Consumer Research, 27(4), 412-432.

O'Reilly, T. (2005). What is Web 2.0: Design Patterns and Business Models for the Next Generation of Software. Accessed 15.10.2013 URL: http:/www.oreillynet.com/pub/a/oreilly/tim/news/2005/09/30/what-is-web-20.html.

Paasonen, S. (2009). Affektiivisia miniatyyrimaailmoja: Tytöt ja muotinuket brändiyhteisössä. Nuorisotutkimus, 4(27), 3-19.

Reid-Walsh, J. \& Mitchell, C. (2004). Girls' Web Sites: A Virtual "Room of One's Own"? In Harris, A. (ed.), All About the Girl: Culture, Power, and Identity. New York: Routledge, pp. 173-182. 
Sicilia, M. \& Palazón, M. (2007). Brand Communities on the Internet: A Case Study of Coca Cola's Spanish Virtual Community. Corporate Communications, 3(13), 255-270.

Suoninen, A. (2013). Lasten mediabarometri 2012: 10-12-vuotiaiden tyttöjen ja poikein mediankäyttö. Accessed 12.9.2103. URL: http://www.nuorisotutkimusseura.fi/julkaisuja/lastenmediabarometri2012.pdf

Vänskä, A. M. \& Autio, M. (2009). Aikuisia lapsia ja lapsiaikuisia - symbolinen lapsuus visualisoituvassa kulutuskulttuurissa. Nuorisotutkimus, 4(27), 53-69.

Ylitapio-Mäntylä, O. (2011). Reflecting Caring and Power in Early Childhood Education: Recalling Memories of Educational Practices 3(57), 263-276. Scandinavian Journal of Educational Research. Accessed 3.8.2012. URL: http://www.tandfonline.com/doi/abs/10.1080/00313831.2011.637230. 